\title{
Pore network modeling of water block in low permeability reservoirs
}

\author{
Shao Changjin*, Yang Zhenqing, Zhou Guanggang and Lu Guiwu
}

College of Sciences, China University of Petroleum, Beijing 102249, China

(C) China University of Petroleum (Beijing) and Springer-Verlag Berlin Heidelberg 2010

\begin{abstract}
A pore network model was used in this paper to investigate the factors, in particular, throat radius, wettability and initial water saturation, causing water block in low permeability reservoirs. A new term - 'relative permeability number' (RPN) was firstly defined, and then used to describe the degree of water block. Imbibition process simulations show that the RPN drops in accordance with the extension of the averaged pore throat radius from 0.05 to $1.5 \mu \mathrm{m}$, and yet once beyond that point of $1.5 \mu \mathrm{m}$, the RPN reaches a higher value, indicating the existence of a critical pore throat radius where water block is the maximum. When the wettability of the samples changes from water-wet to weakly water-wet, weakly gas-wet, or gas(oil)-wet, the gas RPN increases consistently, but this consistency is disturbed by the RPN dropping for weakly water-wet samples for water saturations less than 0.4 , which means weakly waterwet media are more easily water blocked than water-wet systems. In the situation where the initial water saturation exceeds 0.05 , water block escalates along with an increase in initial water saturation.
\end{abstract}

Key words: Pore-network model, water block, relative permeability number, low permeability, wettability

\section{Introduction}

The migration and accumulation of water in the nearwellbore region cause a reduction in relative permeability to gas, thereby decreasing the gas well productivity. This is known as water block. Water block may result from the invasion of water-based drilling fluid, completion fluid, fracturing fluid, workover fluid or emulsions, or from fingering or coning of formation water.

Of all the various factors causing water block, rock wettability, clay swelling, and initial water saturation are of paramount importance. Numerous laboratory investigations into water block have been reported (Huang and Holm, 1986; Lin, 1990; Land, 1990; Zhou, 2005; Zhong, 2008). Recent experimental data from Zhang and Austad (2006) showed that the oil recovery was tremendously improved by increasing the sulfate concentration in the imbibing fluid, and that the wettability modifying property of sulfate increased as the temperature increased. Tripathi and Mohanty (2008) applied a viscous fingering model to describing the instability due to wettability alteration in displacements through porous media. The extreme cases of water block occur when formation matrix in the near-wellbore region is subject to clay particle invasion or clay swelling. Since Milton studied the effect of clay swelling and fines migration on formation permeability, so far two types of mechanisms for clay swelling have been

*Corresponding author. email: physics@cup.edu.cn

Received July 10, 2009 identified (Milton et al, 1961; Amorim et al, 2007): crystalline swelling and osmotic swelling, enabling us to determine the compatibility between reservoir clays and foreign fluids and to avoid the osmotic swelling conditions which can cause permeability reduction in natural hydrocarbon reservoirs. The water blocking damage as a function of initial water saturation was studied by gray association analysis (Zhang and Yan, 2002; Sun et al, 2009); however, no experiments have been done so far to verify the result.

Due to the diversity of the factors causing water block in porous media, the results from core experiments must be accordingly diverse. In this paper, we single out three factors: pore geometry, wettability, and initial water saturation as the primary ones for the current research focus with reliance on pore network modeling.

\section{Modeling method description}

In pore-scale modeling, hydrocarbon recovery processes were simulated directly on the microscopic scale of single pores, without assuming a priori the traditional macroscopic equations (such as Darcy's law) of conventional reservoir simulation. This was done by creating a virtual rock consisting of pore bodies and pore throats of different sizes (the $\square$ geometry $\square$ of the rock) variably connected to each other (the $\square$ topology $\square$ of the rock) and then simulating in it the hydrocarbon recovery process of interest on the microscale, with the relevant physics implemented on a pore to pore basis.

This technology can provide difficult-to-measure multi- 
phase flow data (relative permeabilities and capillary pressures) in a fast and efficient way and can explore the sensitivity of these data to a variety of experimental conditions. The scope for utilization of pore-scale network modeling is in fact much wider and extends to the study and optimization of recovery processes whose physical mechanisms are not yet understood (such as reservoir depressurization) and to other cases where laboratory investigation would be time-consuming, costly or technically very difficult.

The pore network model used in this paper is a realistic representation of a sample of a tight gas sand reservoir reconstructed from the 3D micro-focused X-ray CT image. Detailed descriptions of its reconstruction, validation, along with relative permeability computing theories were discussed by Blunt et al (2002). The domain size of the pore-networks was chosen to be $20 \times 20 \times 20$ grids, roughly corresponding to the physical dimension of $20 \mu \mathrm{m} \times 20 \mu \mathrm{m} \times 20 \mu \mathrm{m}$ in the $x$-, $y$ - and $z$-directions, as we used in an earlier paper (Yang et al, 2007). In this model, 10 percent of these elements are squares, 5 percent circular, and the rest irregular triangles.

Bennion et al (2000) documented the existence of reservoirs, which exhibit an average initial water saturation less than the irreducible water saturation. For these reservoirs, water is easily trapped within the reservoir due to spontaneous imbibition, which may reduce the productive capacity of the reservoir. It is very difficult to increase the productive capacity to its initial value because it requires a transition from an equilibrium to a non-equilibrium state to remedy the damage. In view of the current reality, the primary drainage (gas displacing water) continues until a maximum capillary pressure is reached; then the secondary imbibition (water displacing gas) is simulated in which the water block occurs. By changing the parameters, a parametric study of imbibitions is carried out. The controlled parameters used here are the advancing contact angles, the fraction of gasand/or oil-wet pores, the interfacial tension, and the initial water saturation. Once the secondary imbibition is completed, the major displacement mechanisms, capillary pressures, relative permeabilities, and trapped gas saturations are reported.

Despite the fact that so far no specific physical term has been advanced to quantitatively describe the water block phenomenon, it is common knowledge that water block is prone to reduce gas and/or oil permeability on a large scale, leading to the range shrinkage of mobile fluid saturation as shown in Fig. 1. The extent of relative permeability reduction depends on the phase behavior of the fluid, i.e. relative permeability has different values for varying fluid saturation; therein, at different saturation, the degree of permeability reduction is not the same. To reflect the whole change of relative permeability, one should integrate relative permeability reduction over saturation, so in this paper we define a term - relative permeability number (RPN) to depict the change in permeability; it is the area under the relative permeability curve when the water block occurred. For the water-gas two-phase system, the gas permeability is the main concern, which leads us to calculate the integration of relative permeability along the gas permeability $\left(k_{\mathrm{rg}}\right)$ curve.

$$
\delta=\int_{0}^{1} k_{\mathrm{rg}}\left(S_{\mathrm{w}}\right) \mathrm{d} S_{\mathrm{w}}
$$

where $S_{\mathrm{w}}$ is water saturation; $\delta$ is the relative permeability number.

The water blocking ratio (WBR) is characterized as the percentage ratio of the difference between the undamaged and damaged permeability to the undamaged permeability. With the quantity RPN, we rewrite the WBR as:

$$
R_{\mathrm{wb}}=\frac{\delta_{\mathrm{rk}}-\delta_{\mathrm{r}}}{\delta_{\mathrm{r}}}=1-\frac{\int_{0}^{1} k_{\mathrm{rg}}\left(S_{\mathrm{w}}\right) \mathrm{d} S_{\mathrm{w}}}{\int_{0}^{1} k_{\mathrm{rg}, \mathrm{r}}\left(S_{\mathrm{w}}\right) \mathrm{d} S_{\mathrm{w}}}
$$

where $R_{\mathrm{wb}}$ is the water blocking ratio; the subscript $\mathrm{r}$ here means the reference relative permeability curve.

The undamaged permeability can be obtained with an apparatus subjected to initial baseline flow with either reservoir crude oil or reservoir gas in practice. However, for numerical simulation, we just specified reference permeability as the undamaged permeability, which is supposed to have no effect on our result, as we are primarily concerned with the relative importance of factors affecting water block rather than with the precise evaluation of formation damage. For convenience, the reference relative permeability was obtained with the following conditions: water-wet rock, pore size parameters designed as case $\mathrm{A}$ in Table 1 , advancing contact angles $\theta_{\mathrm{a}}=45^{\circ}-62^{\circ}$, interfacial tension $\sigma=10 \mathrm{mN} / \mathrm{m}$.

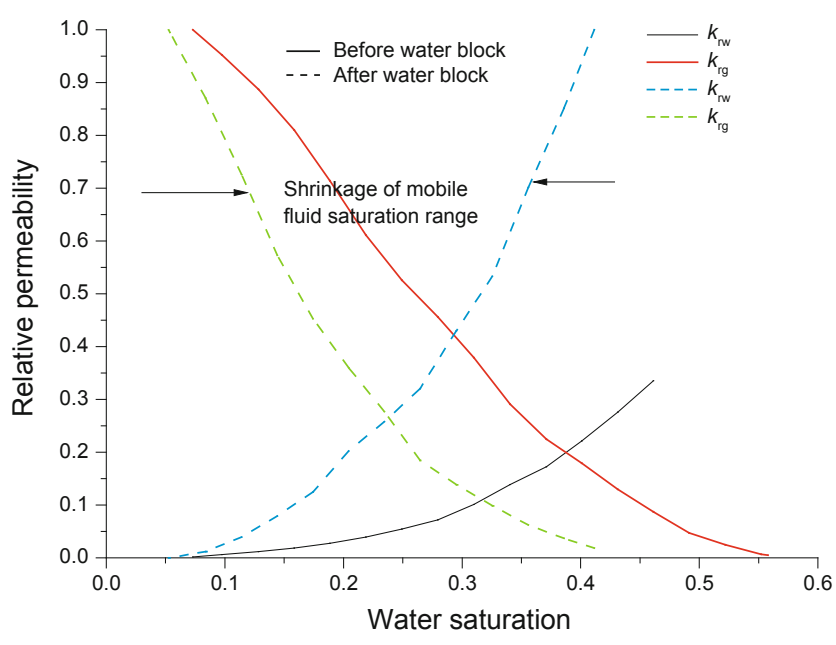

Fig. 1 Relative permeability curves before and after water block

\section{Results and discussion}

\subsection{Effect of pore size distribution}

To evaluate the effect of pore size distribution on the relative permeability of rocks, seven pore network realizations (A-G) with broad, truncated Weilbull pore size distributions were constructed, and the parameters of each pore network are listed in Table 1. 
Table 1 Pore size distributions and parameters

\begin{tabular}{|c|c|c|c|c|c|c|c|}
\hline $\begin{array}{l}\text { Pore network } \\
\text { case }\end{array}$ & $\begin{array}{l}\text { Min. throat } \\
\text { radius, } \mu \mathrm{m}\end{array}$ & $\begin{array}{l}\text { Max. throat } \\
\text { radius, } \mu \mathrm{m}\end{array}$ & $\begin{array}{l}\text { Average throat } \\
\text { radius, } \mu \mathrm{m}\end{array}$ & $\begin{array}{l}\text { Porosity } \\
\varphi\end{array}$ & $\begin{array}{l}\text { Permeability } \\
k, 10^{-3} \mu \mathrm{m}\end{array}$ & $\begin{array}{c}\text { Relative permeability } \\
\text { number } \delta\end{array}$ & $\begin{array}{c}\text { Water blocking } \\
\text { ratio } R_{\mathrm{wb}}\end{array}$ \\
\hline A & 0.05 & 0.2 & 0.109 & 0.123 & 0.04 & 0.202 & - \\
\hline B & 0.05 & 0.4 & 0.187 & 0.289 & 0.29 & 0.715 & 0.13 \\
\hline $\mathrm{C}$ & 0.05 & 0.8 & 0.343 & 0.220 & 0.66 & 0.145 & 0.28 \\
\hline D & 0.05 & 1.5 & 0.620 & 0.215 & 2.06 & 0.131 & 0.35 \\
\hline E & 0.05 & 7.0 & 2.770 & 0.266 & 60.12 & 0.176 & 0.13 \\
\hline F & 0.05 & 10.0 & 3.957 & 0.274 & 128.64 & 0.191 & 0.05 \\
\hline G & 0.05 & 15.0 & 5.880 & 0.276 & 288.35 & 0.186 & 0.08 \\
\hline
\end{tabular}

Fig. 2 shows the simulation results for imbibition process. As shown clearly in Fig. 2, the gas permeability decreases as the water saturation increases (especially at water saturations greater than $10 \%$ ), and the gas relative permeability comes to nearly zero when the water saturation is greater than $50 \%$.

Different pore size distributions produce diverse permeabilities. In general, permeability of the samples varies with pore size distribution in an obscure fashion, which was proved by Crowell et al (1966) with experiments, in which they investigated four sandstone core samples and concluded that the relative permeability of gas-water two-phase system has no apparent correlation with the absolute permeability.

Nevertheless, an interesting phenomenon is found. When the maximum pore throat radius is less than $1.5 \mu \mathrm{m}$, an increase of the average throat radius brings about a drop in calculated RPN value and yet a rise in the calculated WBR value, as shown in Table 1. Once the maximum throat radius is larger than $1.5 \mu \mathrm{m}$, the RPN reaches a higher value while WBR a lower value.

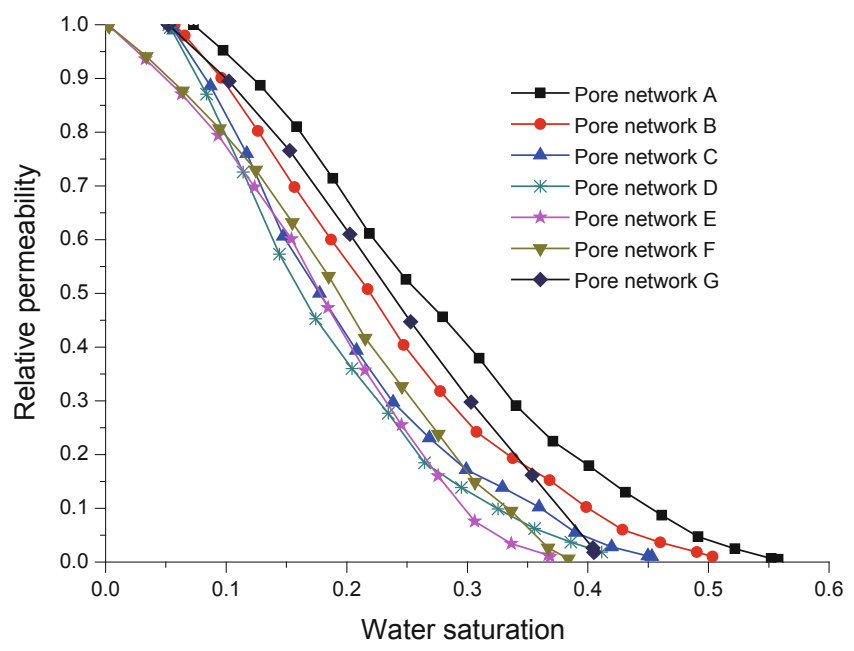

Fig. 2 Gas relative permeabilities at different pore size distributions

This means that, the worst water block does not always occur in the minimum pore throats; instead, the formation consisting of medium-scale throats is much more easily water blocked. There may be a critical value of throat radius where water block is highest, which is, in our calculated cases, 1.5 $\mu \mathrm{m}$.

If the chief throat radius of gas formation happens to fall within the range of 0.2 to $1.5 \mu \mathrm{m}$ (such as $\mathrm{He}^{8}$ in the Changqing Oilfield), the critical throat radius, in view of its critical role in water blocking alleviation, deserves to be given adequate attention. Unfortunately, this has been largely ignored so far. On this account, further investigations into the mechanism are needed in subsequent work in order to fully understand this critical phenomenon and apply it in practice.

\subsection{Effect of wettability}

To discover the influence of wettability alteration on relative permeability, a series of drainage and imbibition simulations are performed on the same pore network (Case A) by changing the range of advancing contact angles. The contact angles used to represent water-wet, weakly waterwet, weakly gas- or oil-wet and strongly gas- and/or oil-wet systems are shown in Table 2.

Table 2 Contact angles used to represent different wettability conditions

\begin{tabular}{cccc}
\hline Case & $\begin{array}{c}\text { Contact } \\
\text { angle* } \\
\text { Degrees }\end{array}$ & $\begin{array}{c}\text { Relative } \\
\text { permeability } \\
\text { number }\end{array}$ & $\begin{array}{c}\text { Water } \\
\text { blocking } \\
\text { ratio }\end{array}$ \\
\hline Water-wet & $25-42$ & 0.2134 & - \\
Weakly water-wet & $50-73$ & 0.2041 & 0.04 \\
Weakly gas- and/or oil-wet & $80-100$ & 0.2430 & -0.14 \\
Gas- and/or oil-wet & $105-120$ & 0.2718 & -0.27 \\
\hline
\end{tabular}

Notes: * Receding contact angles, which are 20 degrees lower than the advancing ones.

As shown in Fig. 3, the gas relative permeability curves change with wettability alteration. In each case of water saturation, the gas relative permeability of the water-wet sample is lowered much more than that of the gas- and/or oil-wet sample. This reveals a potential for field application for improved gas-well deliverability and well injectivity by altering the wettability of rocks close to the wellbore in gas condensate reservoirs from strong water-wetting to 
intermediate gas-wetting. Note that, in the case of water saturations greater than $40 \%$ and the rock wettability changing from water-wet to gas and/or oil-wet, the gas RPN increases consistently, whereas in the case of water saturations less than $40 \%$, this consistency is disturbed by the RPN dropping for weakly water-wet samples.

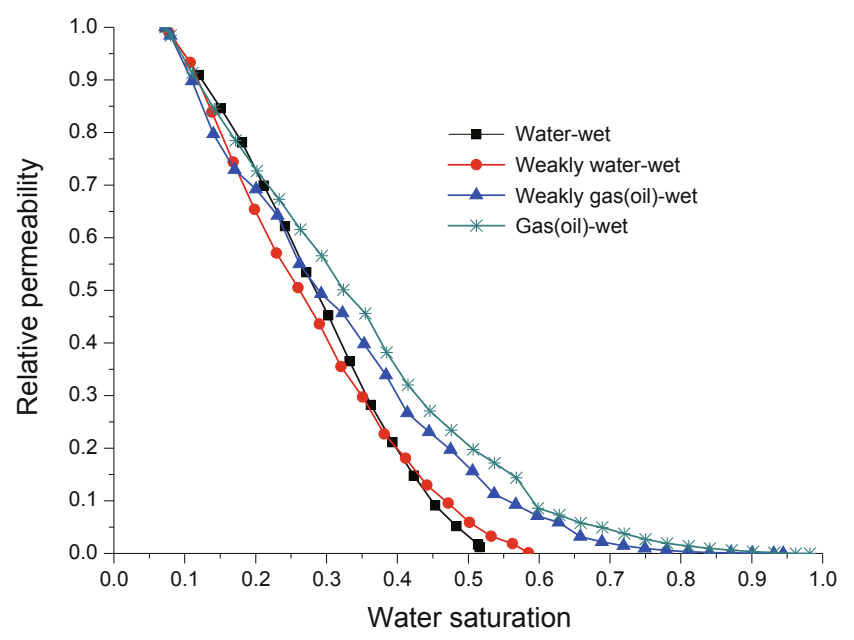

Fig. 3 Gas relative permeabilities at different wettability conditions

The calculated RPN values in Table 2 show a surprising trend with wettability: a weakly water-wet medium is more easily water blocked than a water-wet system, which can be explained as follows.

In water-wet media, water, as the wetting phase (contact angles less than $90^{\circ}$ ), occupy the pores and throats and a water layer, about $1 \mathrm{~nm}$ thick, is formed on the surface of rocks. The pore space has high capillary pressure. During primary drainage, which is similar to gas migration and accumulation in a reservoir, part of the displacement pressure is canceled by the capillary pressure. Therefore, after primary drainage some water still occupies a large part of the pore network. As a result, in the subsequent imbibition process, no more pore space is left to hold flooding water. In this case, the change of total water saturation in the pore space is unnoticeable, responsible for slight water block. This is likely to occur in the reservoirs where the initial water saturation is not too low while the total water saturation is less than $40 \%$. In contrast, the weakly water-wet systems (contact angles close to $90^{\circ}$ ) display many distinct surface characteristics. Gas, as the most non-wetting phase, is not prone to form layers on the rock surface, and with consequent lower capillary pressure the powerful drive pressure is left to displace the water out from pore space during primary drainage, responsible for the great capacity of holding water within the volume of the whole rock throughout the whole imbibition process. In the case of weakly gas-wet media, gas is the most non-wetting phase and no gas layer is formed on the rock surface. When water invades the pore space, the gas directly contacts the pore wall and occupies the pore space, leaving a layer of gas sandwiched in between (i.e. a thin gas layer in the center) and in the corners. Hence, water block is likely to occur. In the case of gas-wet media, the amount of trapped gas is dependent on the ability of the gas phase to form layers; once the layers hold the pores and throats, water block is not likely to occur.

The negative values of the calculated WBR in Table 2 is ascribed to our choice of water-wet case as reference. If the gas(oil)-wet case was chosen, the same as the case in practice, the WBR for water-wet is supposed to have positive value, signaling the occurrence of water block.

\subsection{Effect of initial water saturation}

Five different cases listed in Table 3 were designed to investigate the effect of initial water saturation $\left(S_{\mathrm{wi}}\right)$ on gas relative permeability and water block, with initial water saturations ranging from 0 to approximately $30 \%$. The simulations were performed on the same pore network (Case A). Fig. 4 illustrates the variation in gas permeability with initial water saturation. As for the water-wet networks, the increase in initial water saturation does not elicit large-scaled changes of the trapped gas saturation; however, the calculated results in Table 3 show that the RPN decreases with increasing initial water saturation when $S_{\mathrm{wi}}>0.10$, signifying the growing gravity of water block.

Table 3 Five cases of different initial water saturations

\begin{tabular}{ccc}
\hline $\begin{array}{c}\text { Initial water } \\
\text { saturation }\end{array}$ & $\begin{array}{c}\text { Relative permeability } \\
\text { number }\end{array}$ & $\begin{array}{c}\text { Water blocking } \\
\text { ratio }\end{array}$ \\
\hline 0 & 0.202 & - \\
0.10 & 0.208 & -0.03 \\
0.16 & 0.157 & 0.22 \\
0.24 & 0.083 & 0.59 \\
0.30 & 0.044 & 0.78 \\
\hline
\end{tabular}

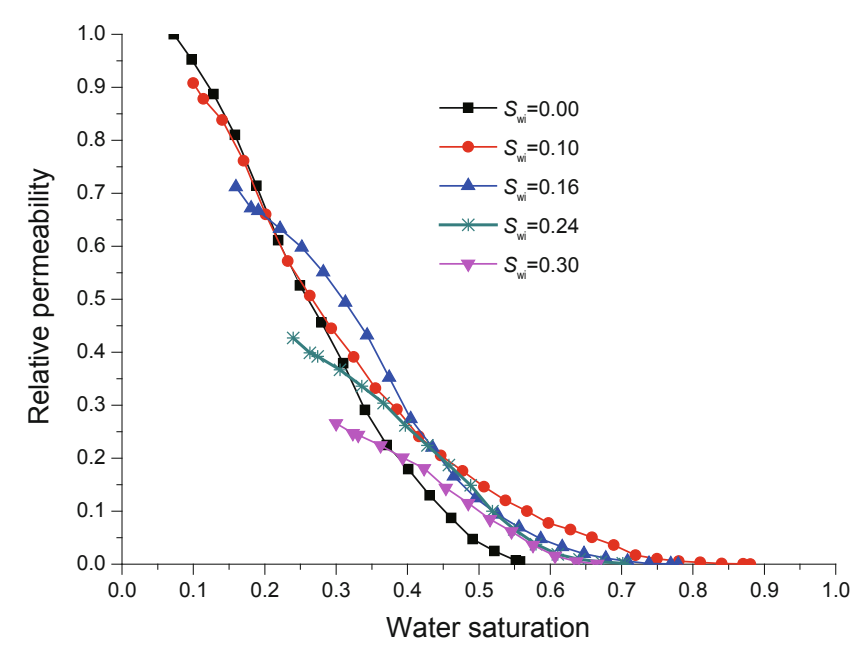

Fig. 4 Effect of initial water saturation on gas relative permeabilities

Investigations done by Coskun and Wardlaw (1995) suggested that the negative correlation between permeability and initial water saturation, which have been commonly used for prediction of saturation, is far from consistent; instead 
it varies along with pore size variation. Significant negative correlation between permeability and initial water saturation has been found in the case of rocks with relatively uniform pore systems but different pore sizes.

In practice, when water saturation is altered from initial water saturation to irreducible water saturation and even to $100 \%$ during well operations, water block is believed to occur. Notice that, in the conventional reservoirs, there exist a wide range of water saturations at which both water and gas can simultaneously flow, which cannot be equally applied to the tight gas reservoirs. In some extreme cases, virtually, no mobile water phase occurs even at very high water saturations. So, irrespective of some researchers' claims of the critical role played by initial water saturation in water block, it remains controversial for the time being.

\section{Conclusions}

The relative permeability number (RPN) defined in this paper is proved to be quite illustrative in presenting the general pattern of permeability changes with saturation, which is more suitable for describing the water blocking phenomenon. Armed with this concept and simulation experiment, we draw the following conclusions:

1) In the case of throat radius within the range of $0.05-1.5$ $\mu \mathrm{m}$, the RPN decreases with an increase in the averaged pore throat radius, whereas the RPN reaches a higher value when the maximum throat radius is larger than $1.5 \mu \mathrm{m}$, indicating the existence of a critical pore throat radius at which the water block is highest.

2) Weakly water-wet media are more easily water blocked than water-wet systems. This reveals a potential for field application for improved gas-well deliverability by altering the rock wettability.

3 ) In the case of initial water saturation larger than $10 \%$, the water block is becoming growingly severe with increasing initial water saturation.

\section{Acknowledgements}

The authors are grateful for financial support from the National Key Technology R\&D Program in the 11th FiveYear Plan Period (Grant No: 2008ZX05054) and the Nonmain Petroleum Subject Cultivating Fund of China University of Petroleum.

\section{References}

Amorim C L G, Lopes R T, Barroso R C, et al. Effect of clay-water interactions on clay swelling by X-ray diffraction. Nuclear Instruments and Methods in Physics Research. Section A, Accelerators, Spectrometers, Detectors and Associated Equipment.
2007. 580(1): 768-770

Bennion D B, Thomas F B and Ma T. Formation damage processes reducing productivity of low permeability gas reservoirs. Paper SPE 60325 presented at the SPE Low Permeability Reservoir Symposium and Exhibition, March 12-15, 2000, Denver, Colorado

Blunt M J, Jackson M D, Piri M, et al. Detailed physics, predictive capabilities and macroscopic consequences for pore-network models of multiphase flow. Advances in Water Resources. 2002. 25: 10691089

Coskun S B and Wardlaw N C. Influence of pore geometry, porosity and permeability on initial water saturation - An empirical method for estimating initial water saturation by image analysis. Journal of Petroleum Science and Engineering. 1995. 12(4): 295-308

Crowell D C, Dean G W and Loomis A G. Efficiency of gas displacement from a water-drive reservoir. Report of investigations, 6735 USBM. 1966. 1-29

Huang E S and Holm L W. Effect of WAG injection and wettability on oil recovery during carbon dioxide flooding. Paper SPE 15491 presented at the SPE Annual Technical Conference and Exhibition, Oct 5-8, 1986, New Orleans, LA

Land C S. Calculation of the water-blocking effect in tertiary miscible displacement. Paper SPE 21626, 1990 (Unsolicited. This document was submitted to SPE (or its predecessor organization) for consideration for publication in one of its technical journals. While not published, this paper has been included in the eLibrary with the permission of and transfer of copyright from the author)

Milton N W, Laverty T R, Bystrom G R, et al. Effect of grain size, grain shape and clay particles on oil recovery by water flooding. Paper SPE 247, 1961 (Unsolicited. This document was submitted to SPE (or its predecessor organization) for consideration for publication in one of its technical journals. While not published, this paper has been included in the eLibrary with the permission of and transfer of copyright from the author)

Sun Y X, Yan J and Jin L. Predict the severity of water lock using grey correlation. Drilling and Completion Fluids. 2009. 26(1): 3-5 (in Chinese)

Tripathi I and Mohanty K K. Instability due to wettability alteration in displacements through porous media. Chemical Engineering Science. 2008. 63(21): 5366-5374

Yang Z Q, Shao C J, Zhou G G, et al. Modeling non-aqueous phase liquid displacement process. Petroleum Science. 2007. 4(3): 40-47

Zhang P and Austad T. Wettability and oil recovery from carbonates: Effects of temperature and potential determining ions. Colloids and Surfaces A: Physicochemical and Engineering Aspects. 2006. 279(1-3): 179-187

Zhang Z H and Yan J N. Prediction of water blocking damage in low permeable sandstone reservoirs. Drilling and Completion Fluids. 2002. 19(2): 1-5 (in Chinese)

Zhong X R, Huang L and Wang L H. Research progress of water blocking effect in low permeability gas reservoirs. Special Oil \& Gas Reservoirs . 2008. 15(6): 12-15 (in Chinese)

Zhou X P, Sun L and Chen C G. Study of water blocking effect in low permeability reservoirs. Special Oil \& Gas Reservoirs. 2005. 12(5): 52-54 (in Chinese)

(Edited by Sun Yanhua) 